\title{
Energy economics and trade for the European Union: The role of seaborne transport
}

\author{
Kyriaki Mitroussi* $^{*}$
}

\begin{abstract}
Energy is a driving force of economic development in the modern world, while as a commodity group it holds the greatest share of the world seaborne trade. Oil, natural gas and coal are the three most important sources of energy for the European Union which, as a bloc, represents 17\% of the total energy consumption. The aim of the present paper is to explore the economics and trade issues of these three major energy commodities and investigate the role of the maritime transport in the energy trade within the context of the EU-25. A number of factors are considered in order to discuss contemporary opportunities and challenges that arise in this context for the shipping business. The examination reveals the critical dependence of EU-25 energy supply on seaborne trade and the considerable reliance of the maritime transport on such commodities for the generation of shipping business within the realms of the EU-25. Among the parameters regarded as conducive to the demand of shipping services in the context of the EU energy trade are the energy demand factor, the import dependency factor, the cost effective production element, and seaborne trade related parameters while consideration is also given to environmental issues.
\end{abstract}

Keywords: Energy demand; Energy trade; Seaborne transport; EU-25;

\section{Introduction}

Energy has a multifaceted presence and impact on the totality of modern life, ranging from everyday human activity to the world economy. It has particularly been associated with economic development and so industrialized areas in the world, like the European Union, exhibit high levels of energy demand.

Energy, however, has not been closely related to the world economic output alone; the major

Submission Date: 11/3/2006 Acceptance Date: 12/15/2006

*Cardiff Business School, Logistics and Operations Management, Aberconway Building Colum Drive Cardiff,

Wales, UK. Tel : +44 292087 6026. Fax : +44 292087 4301. E-mail : mitroussik@cardiff.ac.uk 
energy commodities, namely, oil and its products, natural gas and coal, constitute also the bulk shipments that dominate in the world seaborne trade. Having been long established that the demand for sea transport is, among others, not simply demand for goods but also - and in connection to that - demand for international trade, it is the aim of this paper to investigate the dynamics of the energy economics and trade with a view to exploring the standing of, as well as opportunities and challenges that arise for shipping services in the context of the European Union.

With regard to the international scene, in contemporary times, and in fact generally for the past couple of centuries, hydrocarbons have constituted the primary sources of energy in the world. Extensive research into more environmental-friendly and sustainable energy resources in more recent years has not really brought about any major changes in the distribution of global energy supplies. Oil, gas, and coal predominate in the world primary energy production ${ }^{1}$ and together they represent $88 \%$ of the world's primary energy consumption (Fig. 1). Of equal importance is their presence in international seaborne trade. In fact, much of the growth in world seaborne trade, which for 2004 was $6.9 \%$, can be attributed to an increase in shipments of the aforementioned major categories of energy sources. Based on ton-miles, crude oil and its products together with coal are the most important trades in deep sea shipping (Fig. 2). With oil and coal shipments increasing by about 5\%, LNG shipments by $12.5 \%$ and with an increased average transport distance (UNCTAD, 2005) it is not difficult to illustrate the interrelations and significance of this energy group commodity for the seaborne transport and the demand for shipping services.

For the aforementioned reasons this group of energy commodities - oil, gas and coal - will constitute in this paper the focal point of research and their economics and trade in the EU will serve as the case study for a discussion of maritime economics. In particular, the present study will be concerned with examining these contemporary parameters that have an effect on the demand for shipping services and will explore their application and standing in the context of the energy trade of the EU. In order to do that, we will review, in the first place, two of the most significant factors that trigger demand for shipping, that is, demand for the commodities involved - of oil, gas and coal - and demand for international trade of these cargoes - that is, the external EU trade of oil, gas and coal in the present case. The examination will then focus on another critical factor which is the degree to which maritime transport faces competition from other modes of transport in the trade of oil, gas and coal by investigating the current role of maritime transport in the energy trade of the EU-25. Lastly, our discussion of demand for shipping will be expanded to include a number of other pertinent macroeconomic considerations, such as environmental concerns, as well as an attempt to project and place such considerations within the context of the European Commission expressed future expectations with regard to energy and transport.

\footnotetext{
${ }^{1}$ Data based on the BP Statistical Review of the World Energy 2005, and the IEA, Key World Energy Statistics 2005 representing figures in 2004 .
} 


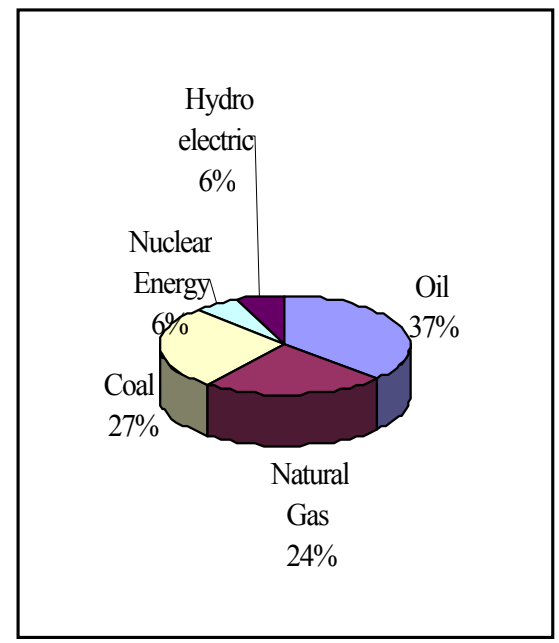

Source: Created with data from BP Statistical Review of the World Energy, 2005

Fig. 1. World's primary energy consumption

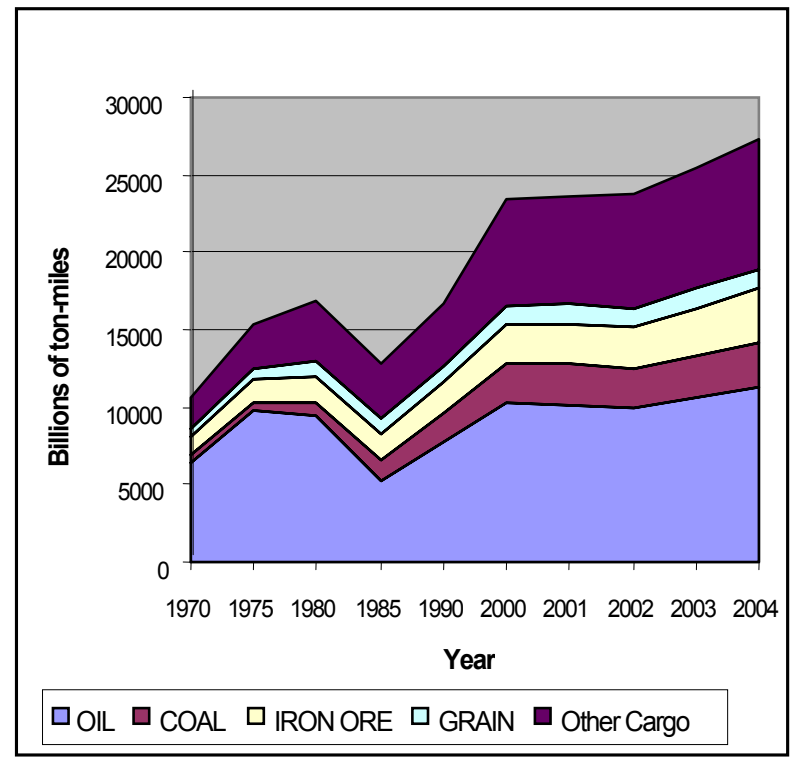

Source: Created with data from UNCTAD, Review of Maritime Transport 2005

Fig. 2. World seaborne trade 


\section{Energy demand in the European Union}

As already mentioned, the primary issue when examining shipping economics in respect of certain commodities, is to establish the extent of demand of the commodities themselves. As a result, one of the first preoccupations of the present study is to look into energy demand in the European Union. The European Union as a bloc, comprising of 25 member states, is the third most important consumer of energy in the world (Fig. 3). The fact that the EU's energy needs have been growing rather modestly over the past 25 years in relation to international standards (Fig. 4), does not diminish the key-role that energy plays in the EU economy. It is in reality indicative of two other major issues: the increasing industrialization of Asian countries, particularly the mounting role of China in the world economy, and the transition of the EU economy to a service-oriented one. As a country's economy matures, the country moves away from infrastructure development and industrial plant towards a more emphasized provision of services. Indeed services growth in the EU is reflected in the fact, for example, that services accounted for $67 \%$ of jobs in the EU-25 in 2003 (Hussain, 2005). With the rising importance of Asian countries in the contribution of industrial output and therefore also in the world energy demand, the EU's share of growth in the energy demand, at a rate of $1 \%$ and $2 \%$ per year, appears inevitably rather moderate in relation to the total world demand.

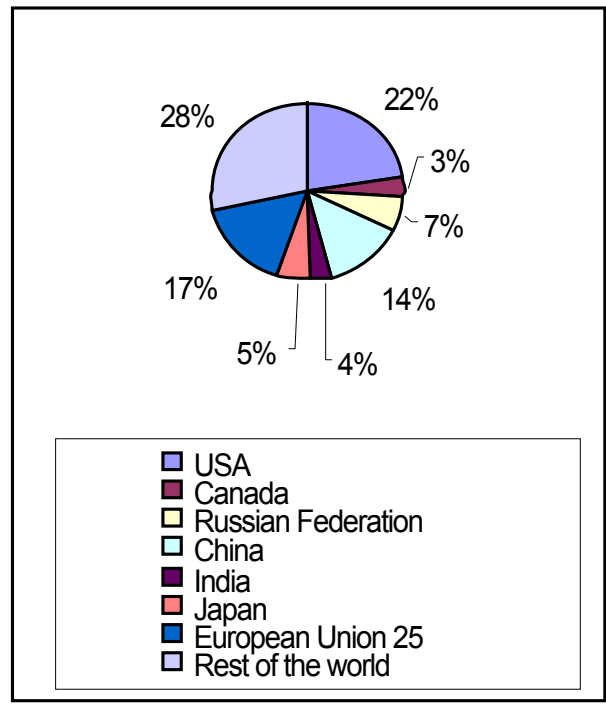

Source: Created with data from BP Statistical Review of the World Energy, 2005

Fig. 3. EU-25 in primary energy consumption 


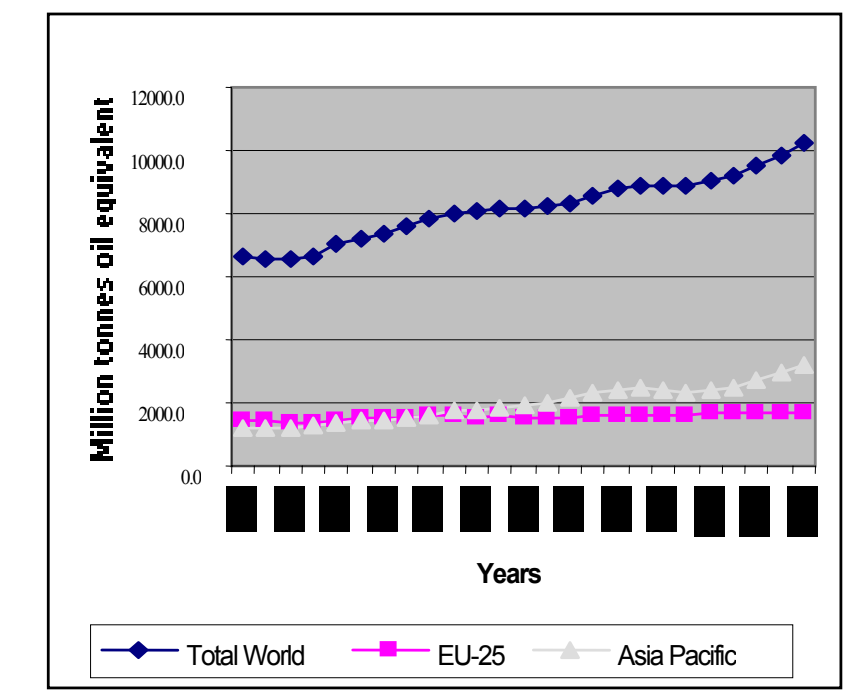

Source: Created with data from BP Statistical Review of the World Energy, 2005

Fig. 4. World and EU-25 energy demand

However, the EU economy remains an energy-intensive economy. Among the EU countries with the highest percentages of energy consumption is Germany with 3.2\% of the world's total consumption, France with $2.6 \%$, the UK with $2.2 \%$, Italy with $1.8 \%$ and Ukraine with $1.4 \%$ of the world's energy consumption. More than two-thirds of the total energy demand is directed to meet the needs of transport, households and the tertiary sector, while industrial demand, which has remained relatively stable over the last 15 years, nowadays accounts for about $28 \%$ of energy consumption for the EU-25 (Fig. 5). Oil is used almost exclusively in transport with a very marginal presence of $1.7 \%$ of electricity, while $60 \%$ of the energy consumption in the industry sector is attributed to collectively coal, oil and gas. In households and services natural gas and oil represent more than half of the energy demand - with natural gas playing distinctly the leading role - followed by electricity, while, quite predictably, coal has only a minor presence. All in all, the EU-25 follows the same universal pattern of an economy heavily dependent on fossil fuels for its energy requirements (Fig. 6). Therefore, demand for oil, gas and coal is quite obviously strong.

As already evident from fig. 6, the EU-25, for a number of reasons and certainly due to it being relatively poor in conventional energy reserves, consumes much more oil, coal, and gas than it produces. With regard to oil, which has the largest share in energy consumption, the EU-25 has benefited, but has not been able to cover its energy needs, from the exploitation of indigenous reserves. North Sea oil production, off the United Kingdom and Norway, began in the late 1970s and has since then experienced periods of upsurge - e.g. 1980-1988 and 1995-2002 - and of decline - more recently in 2004 it witnessed a drop of 10\% from the previous year. Denmark's oil production which started taking place in the early 1970s, has exhibited a continued increase but it currently stands at approximately only 19 million tons, while Italy's oil production does not generate more than 6 million tons a year. 


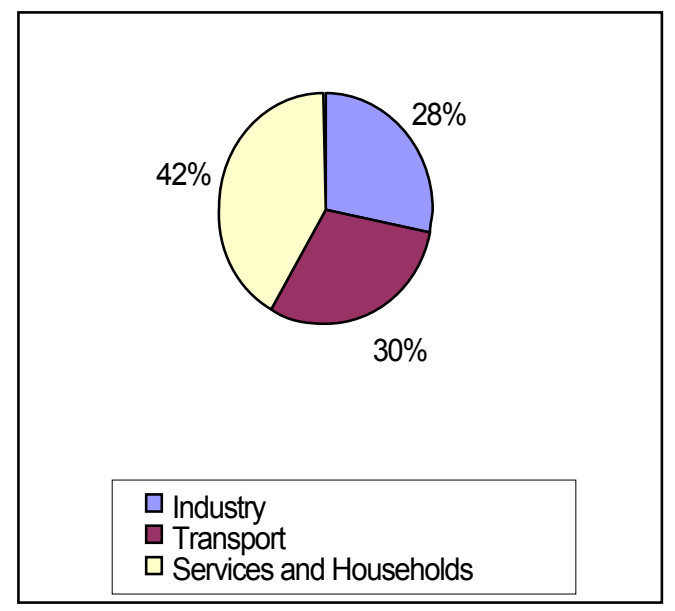

Source: Created with data from Eurostat

Fig. 5. EU-25 final energy consumption by sector

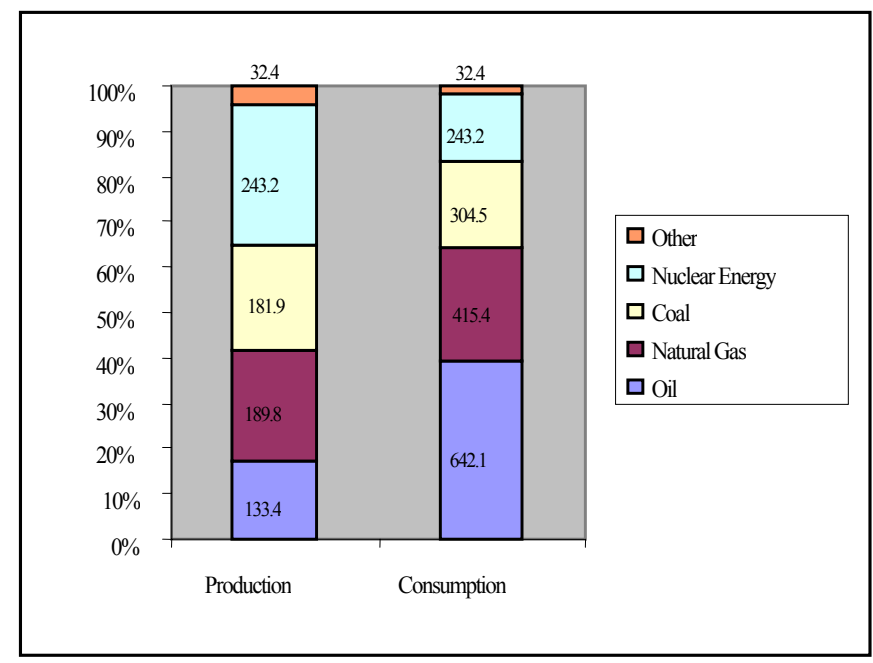

Source: Created with data from Eurostat

Fig. 6. EU-25 energy consumption and production by fuel

With natural gas being by far the fastest growing primary fuel, EU natural gas production, coming principally from the North Sea, has also been on the increase but has, nevertheless been unable to match its consumption rate. Apart from the UK, which is the largest producer but which experienced a $6.7 \%$ decrease in 2004 , the Netherlands is the second most important gas producer and exhibited around $18 \%$ growth in 2004, while Germany, Italy and Denmark are the next most 
significant gas producers in the European Union. There are small volumes of production also in a number of other EU countries, like Poland, Hungary and France.

The case of coal, on the other hand, is a very different one. The reasons for lower production than consumption do not lie this time with a lack of relevant reserves, as the EU has indeed significant coal resources. It is primarily attributed to cost factors. The EU is at a disadvantage due to difficult geological conditions, as it has many deep mines which are expensive to operate, and also due to higher social insurance costs. Both of these factors increase the average cost of producing European coal to be 3-4 times the international market price. Despite substantial subsidies, coal production has been in decline, with several countries, like Portugal, Belgium, France, ceasing all production and others gradually reducing mining activity, to around 180 million tons per year. Following the enlargement in 2004, Poland became the largest of the five producer states in the current EU-25, the rest being, Germany, the UK, Estonia, and Czech Republic. As European coal does not seem to be able to compete with that of the major exporting countries, the EU has been experiencing a consequent increase in the amount of cheap coal imports.

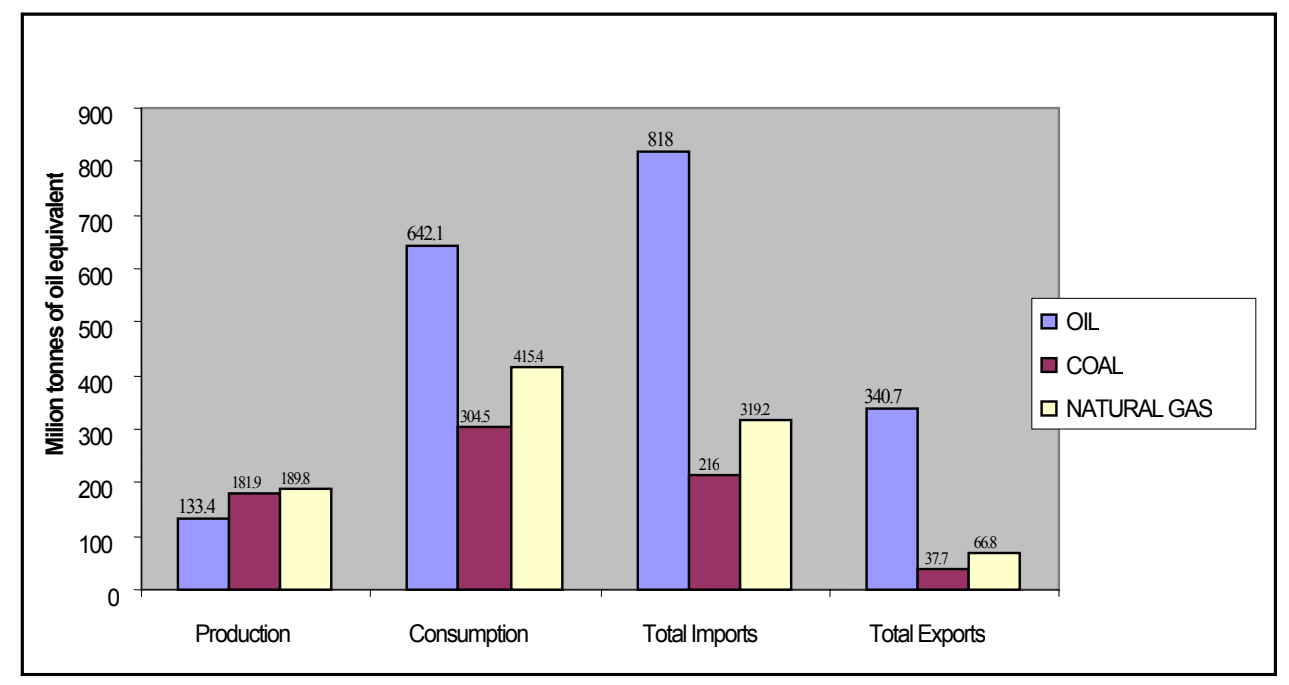

Source:Created with data from Eurostat

Fig. 7. EU-25 production, consumption, imports, exports for oil, gas, coal

In fact, in fig. 7 we can see the joint distribution of production, consumption, imports and exports of all the three energy commodities we are investigating. By far the greatest amount of energy imports are attributed to oil. The EU currently imports around $80 \%$ of its oil, the figure that amounts to $26 \%$ of the world traded oil and makes the EU as a bloc the biggest world importer of 
oil . Its main oil exporters are Russia and Norway, followed by the Middle East, North Africa and West Africa. The European Union is also the most significant importer of natural gas in the world, as again around $77 \%$ of its consumed gas is imported primarily from Russia, and also from Norway, Algeria, and to a much lesser extent from Nigeria and Libya. Interestingly enough a similar percentage of about $77 \%$ of the consumed coal in the EU-25 is also imported by a range of areas and exporting countries. For example, $29 \%$ of the imported EU coal comes from South Africa, 19\% from the Former Soviet Union, 15\% from Australia, 12\% from Colombia and 8\% from the USA (Lefebvre, 2005).

Inevitably, EU-25 exhibits a high degree of dependency on foreign countries for the supply of the energy it needs. In fact, this degree of import dependency has been growing rather than diminishing in recent years. Fig. 8 provides a clear picture of this fact. With regard to coal, EU-25's import dependency rate ${ }^{3}$ increased from $28.4 \%$ in 1992 to $43 \%$ in 2002 . A significant increase in its import dependency was observed also in respect of natural gas, $45 \%$ in 1992, 52\% in 2002. As for oil, despite the fact that the chart shows distinct points of fluctuations, these are attributed to minor differences of approximately 2-3\% each time. With reference to specific EU countries, the states that exhibit the highest degree of energy dependency are in fact some of the largest energy consumers: Germany with $64.6 \%$ in 2004, France with $54.3 \%$, Italy with $87.7 \%$ and Spain with $81 \%$. In 2004 the UK for the first time in over a decade went from being a net exporter to being a net importer with an energy import dependency rate of 5.2\% and so Denmark remained the only net energy exporter in the EU-25. However, there are cases of countries which perform better when looking separately into the three different energy markets, like the Czech Republic and Poland which were net exporters of coal, and the Netherlands a net exporter of natural gas in 2004 (Gikas and Keenan, 2006). Generally, however, what has been established is that within the examined context and due to the overall significant degree of import dependency of the EU with regard to the three most important energy commodities - oil, gas and coal - one more parameter critically conducive to the demand for shipping services can be seen to be fostered; the demand for international trade.

All in all, what has become evident from our examination so far are three important and interrelated issues for shipping economics against the background of the EU-25 energy trade: a) the increased energy demand, b) the overwhelming demand for conventional energy sources, namely oil, natural gas and coal, and c) the increased demand for imported energy sources. These issues, although potentially alarming for the security of the future energy supply of the European Union ${ }^{4}$, create substantial potential for seaborne transport. It is, after all, long established that the demand for shipping services is driven by the demand in international trade. Consequently and before proceeding to a more elaborate discussion of the parameters regarded as conducive to the demand

\footnotetext{
${ }^{2}$ In 2004 it shared this top position of oil imports with the USA.

${ }^{3}$ Energy dependency rate shows the extent to which a country relies on imports in order to meet its energy needs. It is calculated using the formula: net imports / (gross inland consumption + bunkers).

${ }^{4}$ In fact, the European Union has taken a number of steps in order to formulate, promote and support a unified energy policy with the aim of tackling or responding to issues raised, the most well-known example of such steps being the introduction of the 'Green Paper' in November 2000.
} 
of shipping services in the context of the EU energy trade we should examine whether this potential for shipping services created by demand for commodities and trade is actually realized. In the next section, therefore, we will examine the role of maritime transport in the energy trade for the EU-25.

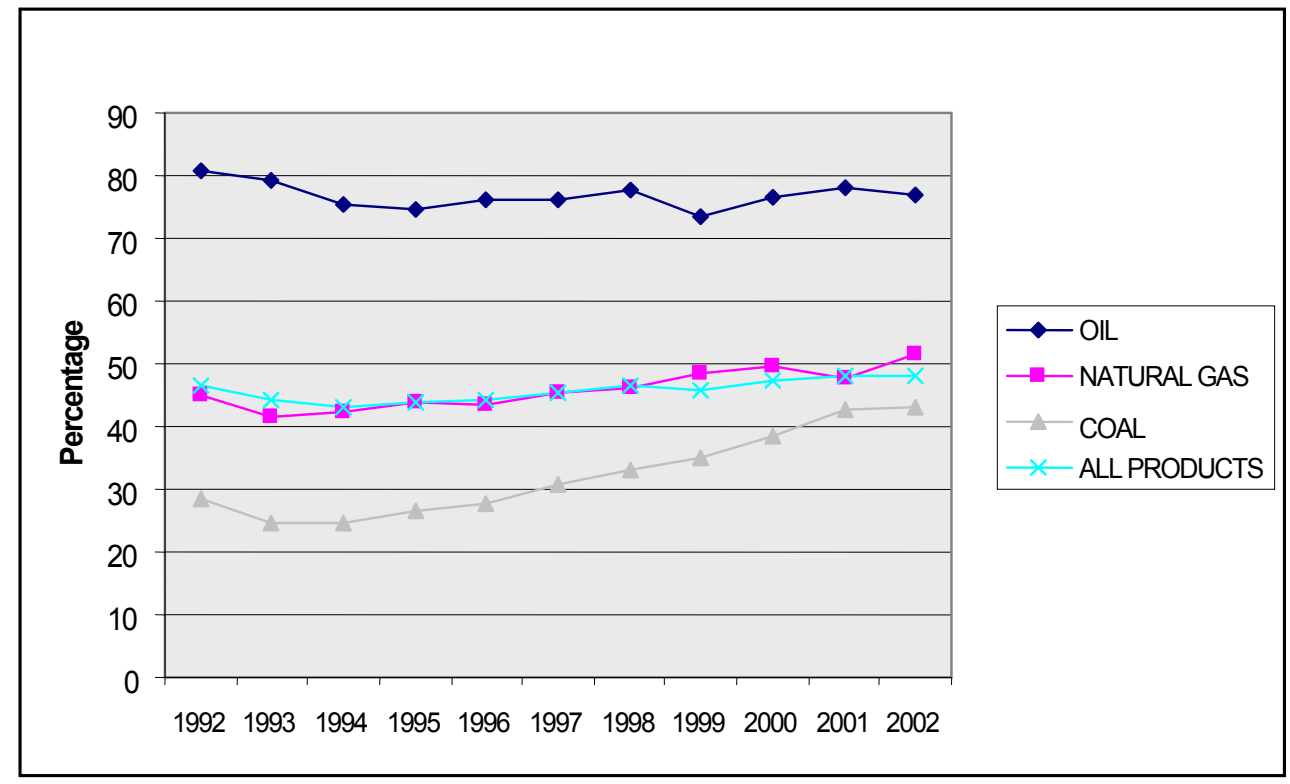

Source: Created with data from Eurostat

Fig. 8. Energy import dependency for EU-25

\section{The role of maritime transport in the energy trade of the EU-25}

EU-25 plays a very important part in international trade. With about 3.5 billion tons of goods transported as part of EU's external trade in 2004 - and that includes both Extra EU-25 and Intra EU-25 trade - the European Union as a group represents around 20\% of the world's trade and shares the top position in global trade with the USA, followed by Japan, China and Canada (European Commission, 2005; Eurostat, 2005). The overwhelming majority, 80\%, of the total volume of extra-EU trade, which has anyway been increasing significantly over recent years, refers to imported goods. The most important mode of transport carrying more than $70 \%$ of all trade between the European Union and the rest of the world is maritime transport (Fig. 9). 


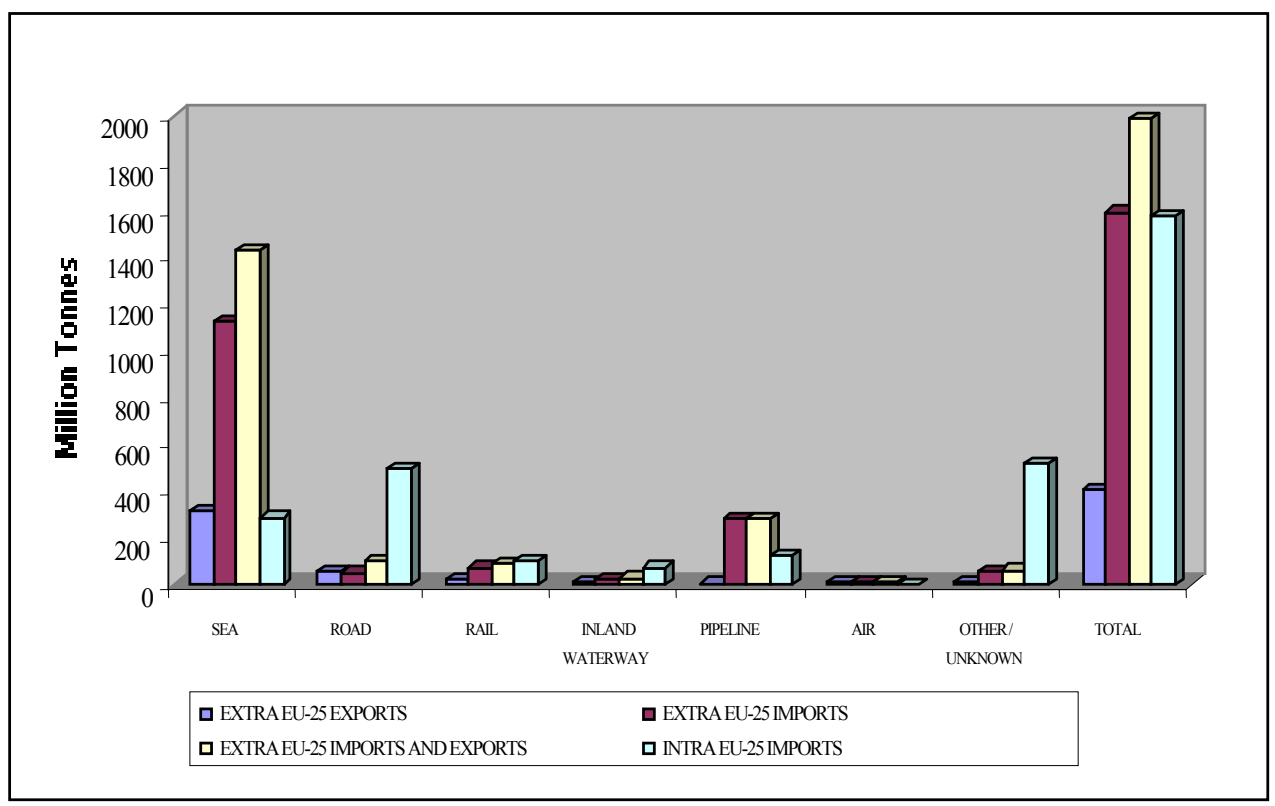

Source: Created with data from Eurostat

Fig. 9. EU-25 external trade by mode of transport in 2004

In terms of the separate EU countries, the UK is the principal state in seaborne transport of goods with Grimsby \& Immingham, Tees \& Hartlepool, and London are the most important ports with respect to cargo volumes handled. Italy and the Netherlands follow with the most important ports, Geneva and Trieste for Italy and Rotterdam and Amsterdam for the Netherlands. Rotterdam plays, in fact, by far the leading role for maritime transport as the volume of goods moved in this region is almost three times the amount of the Antwerp region, which is the next most significant area when ports are considered. Spain, France, Germany and Belgium appear in that order as the other most noteworthy countries as far as gross weight of seaborne goods handled is concerned, with Algeciras, Marseille, Le Havre and Dunkerque, Hamburg and Bremen, and as already said Antwerp, their major ports respectively (Amerini, 2005).

For 16 out of the 20 countries that are actually involved in seaborne trade the commodities unloaded surpass, in most cases by far, the amount of cargoes loaded. On the other hand, in Poland and the three Baltic states, Estonia, Latvia and Lithuania the outward volume was dominant and its share reached 94\% for Latvia and 91\% for Estonia in 2004. The different pattern observed in these countries can be attributed to the presence of natural resources that are transferred via sea to the final user regions. Poland is primarily involved in the trade of dry bulk trade with coal being the major commodity traded. The Baltic States occupy a key transit location for Russian oil exports. Ventspills, the port of Latvia had been connected with the Russian crude oil pipeline system until 
late $2002^{5}$ and after that it has been engaged in shipments of crude oil and petroleum products delivered by rail. Lithuania's port of Butinge, which has enjoyed better relations with its Russian suppliers than Ventspills since 2002, is part of a larger Lithuanian oil and gas complex which includes a refinery and a pipeline network connecting the complex to Russia. Tallinn in Estonia also provides an outlet for Russian fuel oil exports and is a recipient of both crude oil and products by rail. The UK is an example of a country which exhibits quite a balance between volume of goods loaded and unloaded, something which can again be attributed to the presence of natural resources due, that is, to the substantial volumes of North Sea oil. On the other hand, such a trend we can also find in other regions, for example, in Sicilia in Italy, where thanks to the presence of refining plants, crude oil imported from other areas, the Middle East predominantly, is refined and distributed accordingly.

In respect of types of cargoes of seaborne trade in the EU-25, the prevalence of liquid bulk all over Europe is highlighted. Liquid bulk, which includes among different products, crude oil, oil products and liquefied natural gas, makes up $42 \%$ of the total volume of goods transported. Dry bulk cargo is the second most important category of seaborne traded goods in the EU-25, approximately $25 \%$ of total, with Poland and Slovenia exhibiting the highest shares and the Netherlands, the UK, and Spain also handling large amounts. Container transport is especially prominent in Germany and Belgium, whereas the share of Ro-Ro mobile units is highest in the UK followed by Italy, and also considerable for Denmark, Greece and Sweden (Amerini, 2005).

Given that crude oil and oil products make up $78 \%$ of the liquid bulk cargoes handled in the EU25 and that coal has also a very substantial presence in the total EU-25 seaborne trade with a 30\% share $^{6}$, the predominance of liquid and dry bulk cargoes in the EU-25 maritime trade can not but allude also to the significant share energy commodities have in the EU-25 seaborne trade. Fig. 10 and Fig. 11, however, illustrate even more clearly the important role of the maritime transport in the energy trade for the European Union. Fig. 10 shows that the total external trade of the three commodities examined relies to the greatest extent on the maritime transport; this is of course attributed primarily to oil imports and exports and to a lesser degree to coal, while for natural gas the main mode of transport is other than by sea, as it is mainly carried through pipeline networks.

\footnotetext{
${ }^{5}$ In late 2002 the Russian pipeline monopoly stopped deliveries of crude oil to Ventspills following the completion of the port of Primorsk

${ }^{6}$ The percentages refer to 2004 figures.
} 


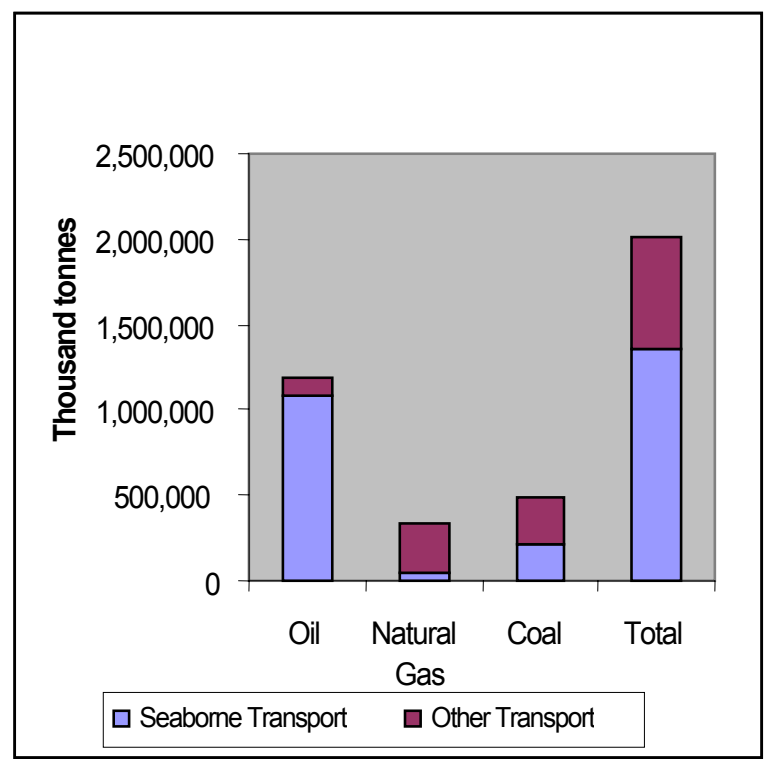

Source:Created with data from Eurostat

Fig. 10. Seaborne transport for oil, gas and coal trade- EU25 2003

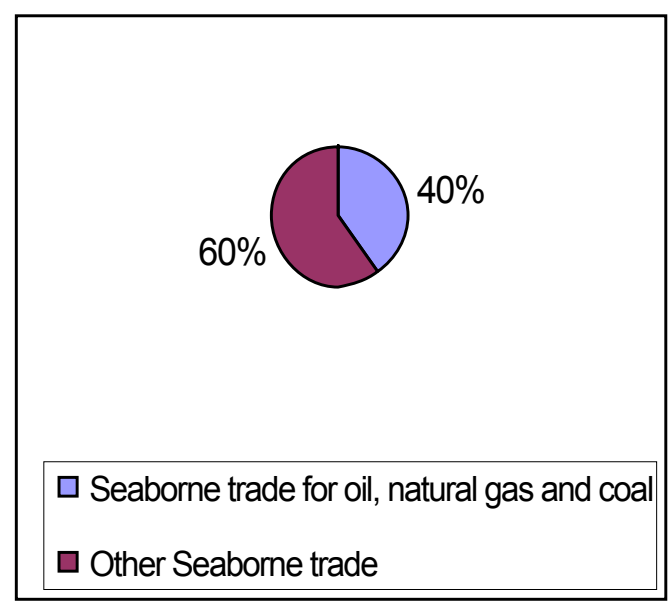

Source:Created with data from Eurostat

Fig. 11. Share of seaborne trade for oil, gas and coal EU-25 2003

On the other hand, in fig. 11 we see that the seaborne trade of oil, gas and coal represents $40 \%$ of the total seaborne transport. If, in addition to these findings, we take into account also the information provided by fig. 5 of the present paper, what we are faced with is a very interesting 
state of affairs; EU-25 energy supply relies predominantly on seaborne trade and at the same time, maritime transport, as part of the general transport, is also heavily dependent on the supply of this energy both for literally its fuel supply as well as and most importantly for the generation of its business. In fact, as we can see in fig. 12 the growth of the seaborne transport for the entirety of the goods handled in recent years has gone hand in hand with the growth of the external trade of collectively the three energy commodities.

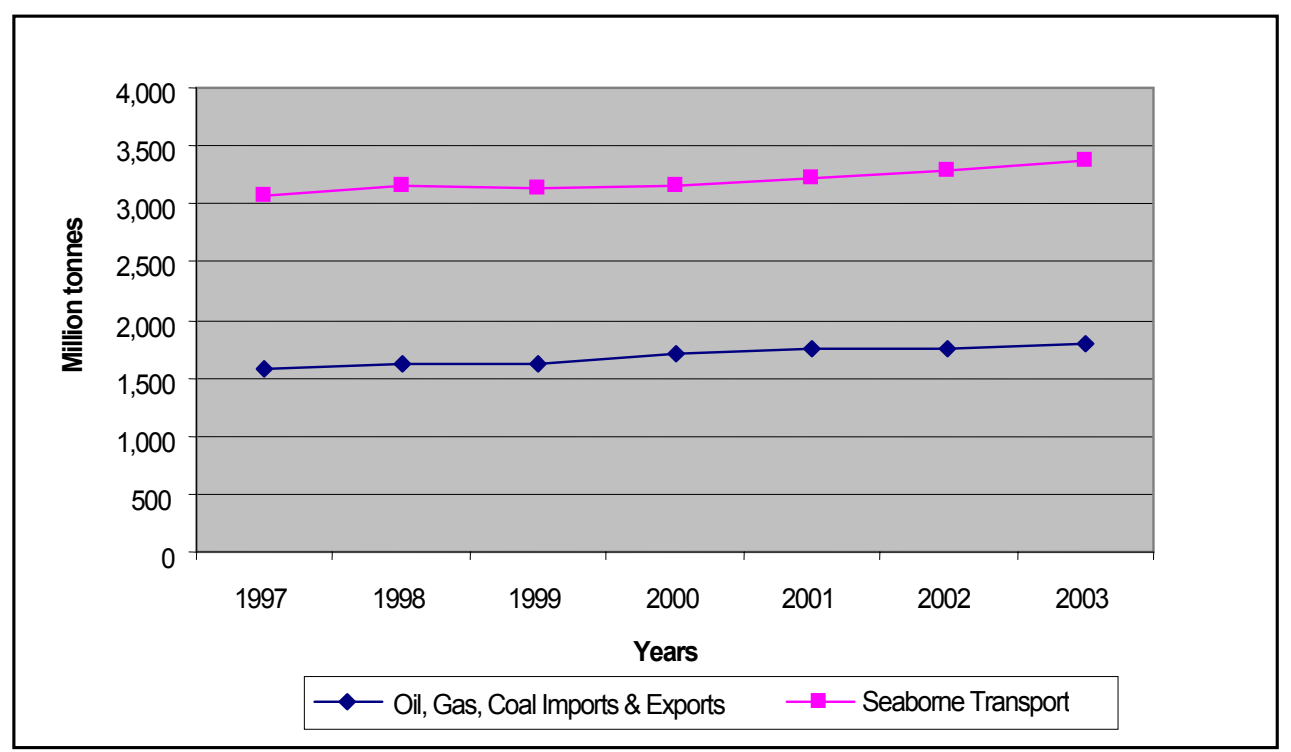

Source:Created with data from Eurostat

Fig. 12. Total trade and seaborne trade growth for oil, natural gas and coal in the EU-25

In essence, therefore, what has been asserted from our examination is the central role played by maritime transport in the trade of the most important energy commodities for the EU-25 and the significant part these same commodities have for the business and the demand of shipping services in the EU-25 context. In the following, we will complement our examination of the main contemporary demand factors for shipping services using the context of the EU energy trade as a case study and attempt to explore future opportunities and threats for the seaborne trade in this context.

\section{Macroeconomic considerations}

Our examination of the standing of the maritime transport in the EU energy trade has revealed that the three energy commodities under study account for much of the shipping business 
generated by the countries forming the European Union of 25. In an attempt to investigate the opportunities and challenges the near future may hold for the seaborne trade within the realms of the EU, we will take into consideration some important macroeconomic factors relating to both the general as well as specifically to the seaborne trade of oil, gas, and coal. Our discussion will mainly include the energy demand parameter, the import energy dependency parameter, seaborne trade related factors, and environmental issues.

\subsection{The demand factor}

The first factor affecting demand for shipping services is of course demand for the goods transported. The recent trends in EU energy demand described above are broadly in line with wellestablished long term trends and with future forecasts. Energy demand is estimated to be still on the rise and indeed $19 \%$ higher in 2030 than in $2000(0.6 \% \text { pa })^{7}$. Looking more closely at the energy consumption pattern we find that the domestic and tertiary sector is the fastest growing segment of final energy demand followed by transport. The relative modest increase in energy demand in the residential sector - due to a rather stable population but even so, with higher living standards - is more than off-set by the growth of the tertiary sector - which reflects the expected restructuring of the EU economy towards services - and by increased transportation activity, which anyway mirrors productive trade activity and human welfare in developed economies. Although, electricity is seen to be gaining an increasing share in energy use by households and the tertiary sector, the predominance as energy sources of gas and oil in this sector and oil in transportation remains an undisputed fact for the whole projected period.

In fact, the carbon intensity of the EU energy system will stay at high levels as it is anticipated that for the next 25 years EU energy demand will continue to be dominated by fossil fuels. Oil is expected to remain the Union's principal source of energy with an $8 \%$ consumption growth and a share of approximately $35 \%$ of total energy demand, while natural gas is predicted to almost equal oil meeting $80 \%$ of the extra demand of energy and representing the $32 \%$ of total energy demand most of its growth being attributed to its rapid penetration in the power generation market. Coal consumption, on the other hand, is seen to decline significantly in the medium term, and although it effectively disappears as a final energy fuel especially in households and services sectors, it is expected to regain its share by $2030(15 \%)$ as replacement for nuclear - due to the decommissioning of a number of nuclear plants - and its price competitiveness in relation to gas.

All in all, the reliance of the EU, to more than $80 \%$, on the three energy commodities examined, oil, gas and coal, for meeting its near future energy needs has become quite clear. In fact, one last observation worth noting here is that if anything, the Commission's approximations produced at the beginning of 2000's seem to have underestimated rather than overestimated the EU's demand

\footnotetext{
${ }^{7}$ The energy related estimates and future projections given in this section are based on: European Commission, Directorate-General for Energy and Transport, The Green Paper 'Towards a European strategy for the security of energy supply' (COM(2000) 769 final of 29 November 2000, European Communities, 2000 and European Commission, Directorate-General for Energy and Transport, European Energy and Transport Trends to 2030, European Communities, 2003.
} 
for these commodities; the estimates for oil, gas and coal for 2010 were 650, 400 and 180 million tones respectively, but in 2004 the actual figures had already reached 695, 420 and 307 million tones respectively (BP, 2005).

Another parameter that can be examined in relation to demand for specific commodities is the substitution effect. In energy consumption the significant alternative sources of energy for the EU are mostly renewable fuels and nuclear power. Despite the fact that some kinds of renewable energy are expected to make exceptional progress in absolute terms, their overall contribution is anticipated to stay rather modest and no more than $8.6 \%$ under the scenarios chosen. As for nuclear power, with the European Commission having a neutral view of nuclear energy and the use of nuclear energy resources being a political decision made by individual states, the future of the nuclear sector is rather uncertain in the Union. A certain number of member states are either opposed to using nuclear power as energy source or have decided to gradually shut down their nuclear power stations. On the other hand, others, like Finland and France plan new nuclear installations and yet others like the Netherlands and Belgium, seem to be adopting a less negative stance towards nuclear power as energy supply. Nevertheless, as it stands the forecast over the next 25 years is that nuclear power will not represent more than around $9 \%$ of the total EU energy consumption. As a result, the prominent position of oil, gas and coal in the EU's future energy needs does not appear to be really challenged by the growth of substitute fuels.

The price factor is also thought to have a bearing on the commodity demand, as any change in its price will affect, positively or negatively, the quantity used or purchased by the consumers. However, for energy commodities this is more true in the long term rather than in the short and medium term and it is indeed true in conjunction with the existence of alternative resources. For example the liberalization of the EU gas market which is under way, would rightfully be expected to bring about competition and in relation to that price competition among suppliers. This will benefit the consumer who will see further potential in turning to gas for the supply of its energy needs. On the other hand, the view has also been expressed that with the rising gas price sometime in the projected period, the EU will turn to the use of cheaper coal, e.g. for power generation. Switching from one fuel to another is not something that can happen overnight; it requires the existence of corresponding infrastructure and of alternative fuels appropriate for the specific use. The case of the residential sector, for example, switching from the use of oil, to the use of natural gas or of the transportation sector, which is so heavily dependent on oil, is characteristic of the long process and substantial costs involved in such energy sources substitution. In times of increases in oil prices it is more likely that in the short term a larger expenditure for energy will be accommodated rather than a dramatic decline in demand. Predictions on the evolution of prices of crude oil have always been difficult to make for a number of geopolitical and commercial reasons, but with more recent oil prices hitting $\$ 70$ a barrel, the likelihood of a return to very low oil prices seems quite distant.

\subsection{The import dependency factor}

For international trade, and also seaborne trade, to be supported, the demand factor for the examined commodities is not the only that needs to be investigated. As already shown earlier by 
fig. 7 and fig. 8 the EU-25 relies greatly on external trade and imports to meet its energy needs. Import energy dependency is connected with the availability of natural resources, the cost-effective energy production in the EU and of course the demand factor especially in relation to the previous two parameters.

The EU's reserves of oil, gas and coal together with the respective world reserves are exhibited in fig. 13. Clearly the EU's reserves are at a disadvantage in comparison to the world's oil and natural reserves with their reserves-to-production rate being 11 and 13 years respectively. The EU-25 has coal reserves in abundance but as coal becomes less popular as a source of energy and due to also other economic factors connected to its production within an EU framework such reserves are not expected to be put into much use in the near future.

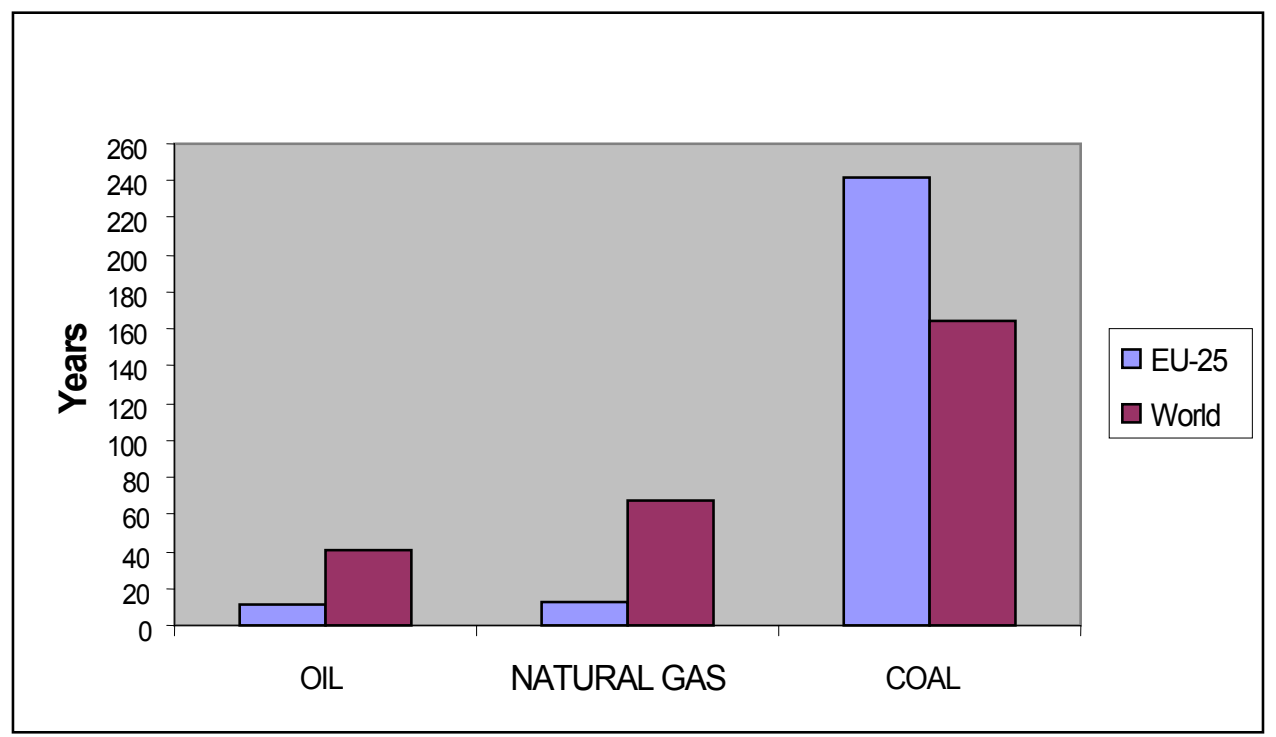

Source:Created with data from BP Statistical Review of the World Energy, 2005

Fig. 13. EU-25 and world reserves-to-production ratio

However, besides a physical depletion, the EU has also to face an economic depletion of its natural energy resources. We have already discussed the effect of the high production costs of coal in relation to the major coal exporting countries and the fact that the problem of competitiveness leads to the EU cutting down production drastically. The exploitation of the North Sea oil fields also presents economic drawbacks. Indeed Europe has benefited from these indigenous reserves but it is characteristic that exploration and production costs are up to three times higher in the North Sea than in the Middle East, for example. As for the natural gas from the North Sea, it follows the same pattern as oil. With regard to discovering new resources in the future, exploiting more costeffective existing ones and developing techniques for ease of use and reduction of environmental 
impact of abundant fuel of coal, technology will play a major role.

Under current circumstances, however, although energy demand is predicted to continue to increase substantially, indigenous energy production does not follow but on the contrary it is projected to drop by $50 \%$ in oil and coal production and $40 \%$ in the natural gas production. As a result, the Union's collective energy dependency on imports from non-member states is thought likely to rise to about $68 \%$ in 2030 with dependence on imported oil reaching $88 \%$, on imported gas the $80 \%$ and coal the $66 \%$. Increased import dependency will therefore inevitably trigger further international trade but additional investigation into a number of other parameters in respect of seaborne trade is needed to complete our overview of the related potential for shipping services.

\subsection{Seaborne trade related parameters}

Shipping competes with alternative modes of transport in the external trade of particularly oil and gas and it is therefore important to examine their role in EU's future energy trade. By far the most significant competitor is the pipeline networks. Pipelines are critical for landlocked crude oil and gas and also form part of an integrated transport system complementing tankers at key locations. Today the EU relies heavily on pipeline networks for the transport and supply of its oil imports from Russia, which is the single most important oil provider country for the EU. At the same time a number of pipeline projects are planned and supported with the aim of relieving the waters around the European Union, especially the Baltic Sea, and also the enclosed Black Sea from increasing intensity of maritime traffic ${ }^{8}$. However, by creating shortcuts and decreasing the distance traveled - in essence the ton miles -, the demand for shipping services also decreases. On the other hand, gas comes from mainly Russia, Norway, and Algeria also via pipelines while LNG supplies mainly from the Middle East, Nigeria, and Trinidad constitute only around 10\% of imported volumes and complement the total gas supply. A number of pipeline projects are also underway for the transport of gas in the $\mathrm{EU}^{9}$. So what is the potential of the maritime transport in this environment?

First of all, the development of new pipeline systems is not without its own challenges, namely political and financial. Political issues, for instance, are of major concern for many transit routes, characteristic examples being the political sensitivity around the Caspian Sea, the closure of pipelines in the Middle East on many occasions due to political reasons and a number of natural gas "transit events" involving Russia which had to do with negotiations or renegotiations of agreements, threats and irregularities in supplies. The other major difficulty is of course the financing of the construction of new route infrastructure from increasingly remote areas to the EU market and the upkeep of existing ones.

\footnotetext{
${ }^{8}$ Such examples include the upgrading and enhancing of the whole Druzhba pipeline and the building of the BurgasAlexandroupolis pipeline to reduce the pressure of maritime oil transport through the Bosphorus.

${ }^{9}$ These include among others: the northern trans-European gas pipeline project which will transport Russian gas under the Baltic Sea to northern Germany and then onwards via the Netherlands to the UK; and the Turkey-GreeceItaly interconnection which will bring the resources of the Caspian region, Iran and the Middle East to the EU market and the Balkans.
} 
On the other hand, one of the most important points addressed in the European Commission's Green Paper for the optimization of the EU energy supply is the diversification of areas of energy imports. Russia has evolved over the past years as the most significant provider of oil and gas for the EU-25 but for a number of reasons the Union is anticipated to secure such supplies from a diverse groups of countries in the future. The recent incident with the threat of the closure of Russian gas lines to the Ukraine ${ }^{10}$ has indicated the politics and costs involved in relying too heavily on a single source. On the other hand, the growing markets of China and other Asian economies and their increasing demand for imported gas could lead to future competition with the European importers for access to the Russian gas resources. Indeed Russia has already exhibited its interest in the Asian market as it is keen to attract investment to develop the oil resources of eastern Siberia and open up new export routes for Russian crude oil to Asia (Wingrove 2005). Even Europe could potentially be seen to have to import oil or gas from distant areas located in Siberia as well as from other distant fields. Specifically with regard to oil imports, the Middle East, already a major oil supplier for the EU and the area with the highest level of oil reserves in the world, will most likely remain for the Union promising large-scale availability of reasonably priced oil and thus for maritime trade a positive contributor as it increases the average haul in the oil trade. The seaborne oil trade may also be helped by other contingencies, one of which could be increased heavy oil product trading with the USA, if, for example, local refineries fail to meet requirements for further lightening and cleaning of a number of oil products.

Imports of liquefied natural gas are also thought to become an attractive alternative to conventional gas as technological progress pushes down supply costs and as gas is brought into the Union from more distant gas fields. Areas in the Middle East, like Iran and Qatar, Central Asia and other North African and Atlantic countries can become new gas suppliers for the EU and indeed the EU will need greater import capacity. It has been shown (Rowe, 2004) that the cost of transporting gas rises in proportion to the distance covered and that in longer distances LNG becomes economically more attractive than pipeline gas, so there seems to be considerable potential for LNG supplies in the EU and so greater demand for such shipping services.

Paramount of course to LNG import growth is the availability of relevant shipping infrastructure, like appropriate terminals. The European Commission through the Green Paper has openly identified priorities for the upgrading and constructing of new LNG terminals and has specifically called for new LNG terminals serving markets characterized by a lack of competition between gas suppliers. Within this context, there are a number of European countries, like Italy, France, Spain and Germany, which are looking to develop LNG facilities. In the UK, apart from the Isle of Grain plant which went into operation in 2005, there are also two more plants being developed in Milford Haven with a starting date in 2008.

As it can be seen, therefore, the seaborne EU energy trade - and demand for shipping services is affected by a number of factors, separate from the demand factor and the import dependency factor. Such particular parameters as described above relate to the availability of competitive alternative modes of international transport, the distance at which suppliers are located, the location of world reserves, geopolitical contingencies, the existence of overall transport policies, like the

\footnotetext{
${ }^{10}$ The Ukraine gas transit network is currently responsible for transporting about $40 \%$ of the EU's gas supplies.
} 
need for diversification in suppliers, competition faced by other countries in terms of energy commodities demand and investment in appropriate infrastructure. There is one more parameter we will examine in the context of our investigation and that is environmental issues.

\subsection{Environmental issues}

With the environment being one significant focus area for the European Union and with energy production, transport and consumption having a direct impact on the environment, it is important to explore the potential effect of relevant environmental considerations and policies on the energy trade and energy maritime transport.

One of the most recent and noteworthy outcomes of such concerns is the conclusion of the Kyoto conference on climate change which took place in December 1997. According to the EU's commitments undertaken at this conference, the EU should reduce its greenhouse gas emissions in the 2008-2012 period to a level of 8\% below the 1990's level. Almost all $\mathrm{CO}_{2}$ emissions generated by man are attributed to the energy sector and the world's - and in that, the EU's - dependence of fossil fuels. Such a commitment favors the use of 'cleaner' natural gas and of course the use of non-fossil fuels in power and steam generation rather than oil and coal. The extent to which the Kyoto undertakings will have an effect on the demand factor for the three examined energy commodities and on the demand for shipping services by the EU region remains to be seen. The fact, however, that so far it appears unlikely that the EU will meet its Kyoto targets, at least through energy related $\mathrm{CO}_{2}$ emissions, as instead of the $8 \%$ reduction in emissions a $7 \%$ increase is projected for 2010 compared to the 1990's level, can only point to continuance of the predominance of the fossil fuels as energy sources for the EU in the near future.

Environmental concerns are also to be found, among other factors, behind projects for the advancement of old and the development of new pipeline networks for the transport of especially oil but of natural gas, too. We have already discussed how the desire to relieve waters around the European Union of increased maritime transport of specifically hazardous and environmental risky cargo has also encouraged investments in pipeline projects. The fact that such cargoes' transport burdens in particular sensitive sea areas, like the Mediterranean, the Baltic Sea and the Black Sea, as well as popular western coast lines, like that of Spain or France, reinforces the argument for the existence and upgrading of such energy transport infrastructure.

Maritime transport does not really have a poor record in respect of safety and environmental protection but it does seem to have a rather 'poor' profile among public opinion - mostly due to highly publicized maritime accidents, involving indeed great oil slicks, off the coast of Western European countries. As such, the maritime transport of oil has also triggered corresponding EU legislation to match that, introducing the concept of 'criminalization' for seafarers in the case of even accidental oil spills.

Furthermore, the North Sea and the Baltic Sea, both heavily used by tankers, are among the first geographical areas in which control mechanisms and restrictions on emissions of sulphur oxide and nitrogen oxide from ship exhausts apply, according to MARPOL Annex VI, which entered into force in May 2005. This has already had a direct effect on transport costs, as tanker operators wish to cover their expenses with regard to use of better quality bunkers when they travel in these areas, 
something which reflects on higher freight rates. In the same lines, coming to terms with increased EU legislation could also mean raising the operating costs, due to, for example, increased crew wages. But the employment of one mode of transport rather than an alternative one is, among others, a matter of competitiveness of transport costs, not to mention that the supply itself of such transport could potentially run the risk of some disruption under the weight of criminalization threat. It is important, therefore, that environmental issues and their possible implications for the EU's seaborne trade are also taken into account in such an examination.

\section{Conclusions}

This paper was concerned with energy trade in the EU-25 and the role of maritime transport in it. In the first place, our examination exhibited the increased energy demand by the EU countries and in particular the overwhelming demand for conventional energy sources, namely oil, natural gas and coal. It was also shown that for a number of reasons, relating to both the absence of adequate natural resources and economic parameters, the EU-25 relies heavily on imports for the required energy supply. In this respect, we recognized the potential for seaborne transport and our investigation revealed a twofold situation; the critical dependence of EU-25 energy supply on seaborne trade and the considerable reliance of the maritime transport on such commodities for the generation of shipping business within the realms of the EU-25.

In the context of the EU energy trade the potential for the demand for shipping services was investigated and a number of factors were found to be conducive to it. These include the energy demand factor, taking also into account the substitution effect and the price effect, and the import dependency factor, which is interconnected with the natural reserves and the cost effective production element. Other related parameters which were examined and found to have a bearing on the demand for shipping services in the context of our study encompass: the availability of competitive alternative modes of international transport, the distance at which suppliers are located, the location of world reserves, geopolitical realities, the existence of relevant transport policies, like the need for diversification in suppliers, competition faced by other countries in terms of energy commodities demand, investment in appropriate infrastructure and environmental considerations.

\section{References}

Amerini, G. 2005. Maritime Transport of goods and passengers 1997-2003. Statistics in Focus. European Communities.

BP. 2005. BP Statistical Review of the World Energy 2005. 
European Commission, Directorate-General for Energy and Transport. 2005. European Union. Energy and Transport in figures 2005. European Communities.

Eurostat. 2005. Europe in figures. Eurostat Yearbook 2005. European Communities.

Gikas, A. and Keenan, R. 2006. Statistical aspects of the energy economy in 2004. Statistics in Focus. European Communities.

Hussain, M. 2005. EU International Trade in Services in 2003. Statistics in Focus. European Communities.

Lefebvre, Jean-Marie. 2005. The coal industry in the European Union in 2003 and 2004. Statistics in Focus. European Communities.

Rowe, Dan. 2004. LNG Market Review. PowerPoint presentation, The Oxford Princeton Programme.

UNCTAD. 2005. Review of Maritime Transport 2005.

Wingrove, M. 2005. Hunt is on for \$200bn investment in eastern Siberia: International companies waiting to pounce as Lukoil seeks foreign partners to exploit major opportunities in Asian markets. Lloyd's List, September 27: 6. 
